\title{
MUSCLE SPASTICITY AND ITS INTERACTION WITH MYOFASCIAL SYSTEM OF CHILDREN WITH CENTRAL PARESIS
}

\author{
Nikolay Moga \\ Department of Orthopedics and Rehabilitation \\ National Pedagogic Dragomanov Uneversity \\ 8/14 Turgenevskaya str., Kyiv, Ukraine, 00154 \\ moga2003@ukr.net
}

\begin{abstract}
Traditionally, the problem of muscle spasticity was considered by experts as a kind of local problem associated with the inhibition or traumatisation of the central motor neuron in a certain part of its path. According to this approach, only the first stage of the causal relationship of the two systems was reflected: the nervous and the muscular systems. In the following, intrasystem relations of the muscle and muscle complex appeared according to the type of harmonization or destructivization of the activity of this system. To resolve this problematic situation, the article examines the original theory of Thomas V. Myers about "anatomical trains" or "myofascial meridians" as an integral musculoskeletal system of the human body, which forms the basis of its anatomy and motor activity. Key ideas of tensegrity as a structure of balanced compression-tension of the musculoskeletal system are identified, and it is necessary to rush to the targets, carrying out the correction of motor disorders of the tender age children with paresis of central type by means of physical education. For deeper understanding of the activities of these mechanisms of children myofascial status harmonization, the main myofascial lines were briefly characterized: surface back line, surface frontal line, lateral line, spiral line, arm lines. On this basis, working hypothesis was formulated as for using the holistic myofascial system capabilities of the child's body to correct both the tonic state of individual spastic muscles and to improve the general children motor status. To check the formulated hypothesis, the directions of the implementation of correctively directed physical education of tender age children with central paresis of different localization levels were indicated. An attempt was made to use the basic knowledge of the myofascial meridians functioning to increase the efficiency of diagnosing the state of musculoskeletal formations of children with spastic paresis, developing strategies and tactics for correcting their tonic state, methods and techniques for adjusting the balance of compression and tension of these structures to improve children motor activity and to improve the efficiency of their basic motor regimes mastering. There was made a fundamental conclusion that the correctional work by means of physical education should be preceded by preparatory work aimed at normalization of the whole myofascial system of a child with a spastic type of movement disorders, which can be carried out using purely medical techniques and the techniques based on the means of children physical education. Prospects of the scientific and practical development of the problem indicated in this article are highlighted separately.
\end{abstract}

Keywords: muscles, fascia, spastic syndrome, tender age children, paresis.

DOI: $10.21303 / 2504-5679.2019 .00954$

\section{Introduction}

The need to improve the physical rehabilitation system of children with spastic types of paresis requires the search of the new reserves for the normalization of muscle tone as the basic background of any motor activity. Muscle spasticity has been studied quite thoroughly [1-3] and, nevertheless, we see a number of insufficiently developed aspects, especially in the systemic understanding of this problem. Most often, spasticity is considered as a phenomenon of a hypertonically contracted individual muscle or muscle group. There are not enough researches dedicated to the systematic study of the whole muscular corset of a body suffering from spastic paralysis and paresis, and this approach could allow finding new approaches to overcome spasticity and to normalize the motor sphere of a child in common [4-6]. A similar concept of the integrated approach has been implemented in Leopold Busk "muscle chains" research [7], but, according to some researchers [8-10], it is mostly based on functional connections between muscles and not on direct fascial joints. 


\section{Aim of research}

To determine the holistic myofascial system of children with central paresis, and at what stage is its relationship with spastic forms of motor disorders of the tender and preschool age children.

\section{The effect of spasticity on "myofascial meridians"}

We find systematic, holistic, conceptual approach to the study of the musculoskeletal complex in the doctrine of Thomas V. Myers about "anatomical trains" or "myofascial meridians" [8]. The term "anatomical trains" is conditional, descriptive, denoting the whole functional system and it is used by the author for figurative comparison with rails, stations, railroad switches, etc., which are so similar to human musculoskeletal structures. A separate anatomical train or path is called "myofascial meridian" by the author, and the word "myofascia" means an inextricably linked structure consisting of muscle tissue ("myo") and the accompanying web of connective tissue ("fascia") [11]. This approach is very interesting for our prospective study, since it becomes clear that the concept of myofascial meridians supposes necessarily, at least mechanical interconnection of any body part with any other body part, even if they are very distant from each other. It is only important to know how these interconnections are carried out, through which channels or meridians they are transmitted. "Bones, cartilage, tendons and ligaments would be filled with thick, dense fiber, and the areas around each joint would be especially well represented. Each muscle would be covered with fiber, and each cell and each group of cells inside of it would be surrounded by the "sweet cotton" of these fibers. Although this network is organized as folded layers, we want to emphasize that no part of this network will be distinct or separated from the network in common. Each of these bags, strings, planes and dense internal grids is connected with all the others "from head to toe". The center of this network can be our mechanical center of gravity, located in the middle part of the lower abdomen with vertical posture.

A truly bold statement is the following: just like the neural and vascular networks do, the fascial web weaves our whole body so much that it is a part of the immediate environment of each cell. If we imagine that the effect of this technique can be extended to the whole body (at the moment this time-consuming work already takes place), then we will get a completely new anatomical picture. We will see how fascial layers organize body fluids into separate streams. We will understand that the intermuscular septa are in fact fixing cables. Dense lumps of joints will turn into connective tissue organs of movement system.

If then we were able to set this picture into motion, we could see how the body reacts to the tensile and compressive forces transmitted through these layers and planes, and assimilates them in all normal movements" [8].

Next, we will consider in what way and in what directions the musculo-fascial formations in the human (child) body interact:

1. Surface back line (SBL) - unites and connects the back surface of the body from the crown of the head to the soles of the feet and has two sections: from eyebrows to knees and from knees to toes. With straightened knees, SBL functions as a single line of interconnected myofascia. The main postural function of this line is to keep the body in a straightened position, preventing its leaning forward. For long-term implementation of this task by the muscles, it is necessary for the muscle mass of this myofascial complex to consist of a large number of slowly contracting, hardy muscle fibers. The fascial skeleton of the surface back line is represented by the fascia of the occipital crest, the "rope cables" of the muscle which straightens the spinal column, the sternal-lumbar fascia, the sacroiliac ligaments, the fascia of the popliteal muscles and the Achilles tendon. The main motor function of SBL is the extension and hyperextension of the whole body and its individual biolinks.

"SBL is one of the most important lines, which mainly controls the posture and movement in the sagittal plane, either by limiting the movement forward (flexion) or by reinforcing the movement back (extension) in case of improper functioning.

And although we speak about the SBL in singular, in a body, of course, there are two SBLs - right and left ones, and if possible, the imbalance between the two SBLs should be observed and corrected before proceeding to work with the other patterns of restriction along this line. 
The most common statement which can be made as for all the lines is as follows: tension, stretching (positive or negative), trauma and movement, as a rule, are transmitted by these lines to the whole structure" [8].

2. Surface frontal line (SFL) - unites of the entire front body surface from the head (two lateral sides of the skull) to the upper surface of the feet. It consists of two sections: from the head to the pelvis and from the pelvis to the toes. It works as a solid line of interacting myofascia during the hip joints extension (when a human is standing). The main postural function of the SFL is to maintain balance with the surface back line, as well as to support it from above, as if pulling up those parts of the skeleton that extend the line of gravity - the face, chest, pubic bone. Besides, the muscles of the surface frontal line protect the vulnerable areas located on the front of the human body and perform a supporting function for the abdominal organs. The main motor function of SFL is the flexion of the torso and hip joints, extension of the knee joints and dorsal flexion of the feet. The muscle component of SFL contains a large number of rapidly contracting muscle fibers. Here we see a kind of functional dualism: the activity of the SBL is expressed in a relatively slow mode of muscle fibers contraction for endurance, while fast, reactive muscle contractions are characteristic of SFL activity. This interaction can be expressed by the following algorithm: while one line contracts, the other one stretches.

Similarly to the surface back line, there are two lines in SFL - to the left and to the right from the median line. "A frontal examination of the patient will allow you to estimate the differences between the right and left sides of the line in common. And though the differences between the right and left sides of the SFL should be eliminated as much as possible before working on the general patterns of the patient's body, a good general guide to the treating of the most cases would be the elimination of any PFL shortening"[8]. The relevance of this statement is greatly enforced if we talk about children with spastic types of paresis when we observe the hypertonus of the flexor muscles and common flexion of the body in vertical position. Ideally, the surface back line should be harmonically balanced by the surface frontal line. In this regard, if we speak about the correctional physical education of tender age children with spastic motor disorders, the attention needs to be paid at the following technique aspects:

1) Local harmonization of the left surface frontal line.

2) Local harmonization of the right surface frontal line.

3) Harmonization of both surface frontal lines.

4) General harmonization of the surface front line and surface back line.

The harmonization of the SFL state can be carried out in the following directions:

a) manual stimulation of muscles with hypertonus (various types of massage);

b) physiotherapy to reduce hypertonus in muscles with hyperreflexia;

c) traction techniques (stretching of spastic muscles): passive (performed by adults) and active (performed by the child himself during special exercises);

d) treatment by position - the adoption of certain fixed postures to overcome the flexor position in the torso and other body biolinks.

Correction of the stretched (weakened) state of the surface back line may include the following methodical directions in the system of correctively directed physical education of children with central paresis:

a) treatment by position (passive adoption of fixed body positions with the physiological position of the skeleton - "shavasana" posture) [12];

b) passive correction with the help of exercises performed by an adult directed to the general skeleton extension on and to the separate body biolinks;

c) extensor hypercorrection (passive) using special devices (fitball, roller, plastic barrel, cylindrical module, etc.) [13];

d) active conscious correction with help of plot, theatrical physical exercises based on measured dramatization.

3. Lateral line (LL) - starts at the lateral surface of the skull in the ear area, covers torso with a double zigzag and descends along the lateral (outer) side of the thigh and lower leg to 
the external side of the foot. The main function of LL in posture is to maintain the balance between the right and left sides of the body, as well as to balance the front and the back parts of the body. The lateral line also serves as a kind of intermediary in transferring of forces between the other surface lines: the surface back line, the surface front line, the hand lines and the spiral line.

As for the motor functions, this line takes part in the lateral inclinations of the body (lateral torso flexion), abduction of the hips and eversion of the feet (turning the inner edges of the feet in the plantar direction).

"Although two other «main» lines have right and left sides as well, both lateral lines are located quite far from each other and from the middle line, and cannot participate in two-sided alignment of the skeleton as SFL and SBL can. Usually, working with LL turns out to be especially important for balancing the right and left sides of the body, which needs to be thought about and what needs to be done at the early stages of treatment" [8]. This remark has a fundamental character for our prospective dissertation research, since we provide correctional education namely of early age children.

Anticipating deeper scientific research using myotonometry, we will assume that in terms of correctional physical education it will be possible to use the features of the lateral line in the following methodic directions:

a) treatment position (passive laying on the side);

b) passive exercises performed by an adult when a child lies on the side;

c) active exercises performed by a child on the playing, theatrical background.

4. Spiral line (SL) - twists with one coil around the body and connects one side of the skull through the back with the opposite shoulder, passes through the front of the body to the same hip, knee and arch of the foot, and then rises along the back of the body and connects the fascia of the skull on the same side on where it began. In certain sense, this line resembles the shape of the number eight - a very harmonious technical structure that allows redistributing the strain on all the parts of any functioning chain. The SL significance for the preservation of the posture consists of the following: it circumflex the body in a double spiral which helps to maintain balance in all the areas. When there is a skeleton imbalance it creates, compensates and maintains twists, rotations and various lateral shifts of the body. The spiral line takes participation in other meridians. The universal function of the SL is to produce spiral and rotational movements of the body. Using the convenient forms of the anatomical trains proposed by Myers, we list those conditional myofascial rails along which the spiral line passes:

1) Belt muscles of the head and neck.

2) Large and small diamond-shaped muscles.

3) Anterior gear muscle.

4) The external oblique abdominal muscle.

5) Abdominal aponeurosis, white line.

6) Internal oblique abdominal muscle.

7) Strain of wide fascia, iliac-tibial tract.

8) Anterior tibial muscle.

9) Long fibular muscle.

10) Biceps of thigh.

11) Sacrocumulus bundle.

12) Sacro-lumbar fascia, muscle straightening the spine.

"SL intersects many other lines, so most of its structures are also involved in other lines" [8]. This statement gives us reason to assume that to increase the effectiveness of the motor disorders correction regarding tender age spastic children with help of physical education; it is allowed to use the possibility of additional correction precisely through the use of the universal function of this line, its participation in the activities of other main lines. In a methodical aspect, this correctional resource can be implemented in the following directions: 
a) after the normalization of SBL, SFL, LL activity, it is necessary to "put in order" the spiral line, since the presence of tension in local zones can distort both the activity of all the above-mentioned main myofascial meridians and the general motor activity of the child, the child's implementation of the main motor modes;

b) in some cases, it will be possible to use the reinforcement (hyperfunctioning) of this line to solve specific correction tasks in physical culture classes;

c) the complexity of the spiral line (it involves about 12 muscular fascial formations) allows to make selective correction of a certain muscle and to achieve the required motor effect.

5. Hand lines. They include the deep front line of the arm, the deep back line of the arm, as well as the surface frontal line of the arm and the surface back line of the arm. This line is extremely important for the observed problem, since children with spastic forms of paresis almost always and in the first place suffer from hands condition. Although the hand line itself is not directly involved in formation of the structural posture pillar, they still matter for posture: the position of the elbow affects the middle part of the back, and the shoulder position affects the neck, ribs and other areas of the body. The motor functions of the hand lines are much more diverse: "Endless everyday activities of studying surrounding objects, manipulating them and reacting to the world around us require the joint work of our hands, arms and eyes, directed along these lines. Hand lines operate at approximately 10 levels of the arm joints to bring an object closer or to push it away, to attract, push away or stabilize our own body, or just to hold some object that we want to examine or change. These lines are inextricably linked with the other lines, in particular with the Lateral, Spiral and Functional lines.” [8].

As you can see, the hands are supervised by four lines, and it indicates the manipulative significance of the upper limbs for the person. Children with spastic forms of paresis definitely have problems with the state of these lines and these problems should be eliminated. "Here is a simple way to estimate the state of the four lines of the model or of the patient arm. Face the patient, take him by the wrist and ask him to lean back from the ankles into the "loop" of own hands while you support his weight. Thus, the patient will be "suspended" by the lines of his hands. If you hold his wrists and hands in the position of lateral rotation, then the patient will feel stretching (or restriction of movement) in the SBAL from the trapezius muscle up to the extensors. If you hold his wrists and hands in the position of moderately strong medial rotation, he will feel a general stretch in the DBAL along the rhomboid muscles and muscles that rotate the shoulder, and further to the end of the line.

To check the frontal lines of the arm, stand behind your patient and pick up his wrists. Ask him to lean forward from the ankles, and support the weight of his body. If you rotate his arms laterally, he will, first of all, feel stretching in SFAL, in the pectoral major chest muscle and the flexor group; and if you rotate his hands medially, then, most likely, he will feel tension to a greater extent in the pectoral major muscle and the rest of DFAL. Probably your patient will not feel stretching in the areas which we are interested in, then you should pay attention at those areas where he feels stretching, because working on length increasing in the indicated areas (again, since fixation of body positions that are customary for the work can significantly maintain tension in the hands) will bring your patient's body closer to "normal", described above configurations" [8].

\section{Research results}

Summing up the description of the musculoskeletal body features, as well as the main myofascial meridians (lines) existing in it, we hypothesize how these structures can be used to correct the physical development and physical fitness of tender age children with spastic paresis:

1) The spastic problem of a single muscle or a group of muscles should be solved not in local direction, but in a complex way, working with the whole myofascial line.

2) Normalization of one or another myofascial line can reduce the local problem of a single muscle or muscle group and substantially change the strategy and tactics of corrective measures by means of physical education. 
3) Working with paired myofascial meridians, it is necessary to adhere to the following algorithm: when relaxing myofascial structures of one line, one should immediately strengthen (stimulate) the myofascia of the antagonist line.

4) In order to normalize a certain myofascial line, it is often necessary to correct the state of other main myofascial lines.

Checking this hypothesis involves the implementation of the following correction measures:

1) Obligatory diagnostics of the main myofascial meridians condition (SBL, SFL, LL, SL, LR and others) before the beginning of the school year (at the beginning of the correction process). To do this, it is necessary to use existing tests and samples, if necessary, to develop our own, which will be adapted to the study of early age children with spastic forms of paresis.

2) Work on the normalization of the myofascial meridians state should be prior to the correctional physical education classes. This stage can be called the preparatory stage of correction.

3) Speaking about tender age children with spastic movement disorders at this stage, passive corrective measures should prevail. Their essence can be as follows [14, 15]:

a) stretching spasm (stress) sections of the myofascial line;

b) increasing the degree of all biolinks freedom of specific myofascial line;

c) improving the functionality of this myofascial line.

\section{Conclusions}

Summarizing the foresaid, it is necessary to make the following preliminary conclusions:

1) Until now, the problem of spastic muscles (especially in cerebral palsy) has been viewed more in a narrowly specialized sense as a separate special phenomenon of pathological muscle hypertension. The systemic capabilities of the global myofascial structure of the body were not fully explored to better understand the phenomenon of spasticity and to search for more effective ways to correct the problems associated with it.

2) The myofascial meridians concept of Thomas V. Myers provides opportunities for a comprehensive, systematic look at the activities of the musculoskeletal system of a person (child) and provides opportunities for the formulation of new methodological and technique provisions of corrective physical education for children of a specified contingent.

3) The work on the normalization of myofascial meridians should constitute a special preparatory stage of correction and always precede the actual classes in correction physical education of early and preschool age children with spastic motor disorders.

Prospects for research in this direction are in search of adequate methods and techniques for normalizing the state of the main myofascial meridians by means of physical education for tender age children with spastic syndrome.

\section{References}

[1] Bronovitskaya, G., Loiko, L. (2014). Ucheniye o myshtsakh (miologiya). [The study of the muscles (myology)]. Minsk: Belarusian state university of physical culture, 142.

[2] Batysheva, T., Bykova, O., Kvasova, O., Shioshvili, V., Platonova, A., Akhadova, L. et. al. (2016). Lecheniye i reabilitatsiya detey so spasticheskimi formami tserebral'nogo paralicha [Treatment and rehabilitation of children with spastic forms of cerebral palsy]. Moscow: Department of Health, 24.

[3] Vlasenko, S. (2014). Reabilitatsionnyy potentsial spastichnykh myshts u bol'nykh detskim tserebral'nym paralichom: diagnosticheskiye i prognosticheskiye aspekty, differentsirovannyye podkhody k vosstanovitel'nomu lecheniyu, [Rehabilitation potential of spastic muscles in patients with cerebral palsy: diagnostic and prognostic aspects, differentiated approaches to rehabilitation treatment]. Simferopol: Crimea Medical Academy named after S. I. Georgievsky, 367.

[4] Yevtushenko, O., Yevtushenko, S. (2006). Suchasni metody likuvannya m'yazovoyi spastychnosti u ditey z orhanichnymy zakhvoryuvannyamy nervovoyi systemy [Modern methods of treatment of muscle spasticity in children with organic diseases of the nervous system]. Donetsk, 26.

[5] Levchenko, I., Prikhodko, O. (2001). Tekhnologii obucheniya i vospitaniya detey s narusheniyami oporno-dvigatel'nogo apparata [Technology training and education of children with musculoskeletal system disorders]. Moscow: Publishing Center "Academy", 192. 
[6] Palchik, A. (2011). Gipoksicheski-ishemicheskaya entsefalopatiya novorozhdonnykh [Hypoxic-ischemic encephalopathy of newborns]. Moscow: MEDpress-inform, 288.

[7] Buske, L. (2011). Muscle chains: Corpus, cervical spine and upper limbs. Vol. 1. Moscow: Ivanovo, 160.

[8] Myers, T. (2014). Anatomy trains. London: Churchill livingstone, 320.

[9] Palchik, A. (2002). Evolyutsionnaya nevrologiya [Evolutionary neurology]. Saint Petersburg: Piter, 384.

[10] Ratner, A. (2005). Nevrologiya novorozhdonnykh: ostryy period i pozdniye oslozhneniya [Neurology of newborns: acute period and late complications]. Moscow: BINOM, Labaratoriya znaniy, 368.

[11] Semenov, D. Chto takoye spastichnost' i kak borot'sya so spastikoy myshts [What is spasticity and how to deal with muscle spasticity]. Available at: http://neurodoc.ru/diagnostika/simptomy/spastichnost.html/

[12] Kozhevnikova, V. (2013). Sovremennyye tekhnologii fizicheskoy reabilitatsii bol'nykh s posledstviyami perinatal'nogo porazheniya nervnoy sistemy i detskim tserebral'nym paralichom [Modern technologies of physical rehabilitation of patients with the consequences of nervous system perinatal damage and cerebral palsy]. Moscow: Magenta, 568.

[13] Kurenkov, A., Batysheva, T., Vinogradov, A., Zyuzyaeva, E. (2012). Spastichnost' pri detskom tserebral'nom paraliche: diagnostika i strategii lecheniya [Spasticity in cerebral palsy: diagnosis and treatment strategies]. Journal of Neurology and Psychiatry, 7 (2), 24-28.

[14] Batysheva, T. (2010). Metodologicheskiye osnovy lecheniya spastichnosti [Methodological bases of the spasticity treatment]. Medico-social aspects of the treatment of spasticity in the practice of a neurologist. Moscow, 6-9.

[15] Ogorodova, I., Zagorodneva, V., Ogorodov, I., Belaya, N. (2013). Morfologicheskiye izmeneniya myshechnogo apparata detey, stradayushchikh spasticheskimi formami DTSP [Morphological changes of children muscular system suffering from spastic forms of cerebral palsy]. Cerebral palsy and other movement disorders in children. Moscow, 67-68. 